\title{
Smoking and inflammatory bowel disease. A case control study
}

\author{
E LINDBERG, C TYSK, K ANDERSSON, AND G JÄRNEROT
}

From the Department of Medicine, Division of Gastroenterology and Department of Occupational Medicine, Section of Environmental Medicine, Örebro Medical Center Hospital, Örebro, Sweden

SUMMARY A population case controlled study of smoking habits at the time of diagnosis was done in 260 patients with ulcerative colitis and 144 with Crohn's disease. Smokers had a decreased risk of acquiring ulcerative colitis in comparison with never smokers (relative risk $0 \cdot 7$ ) which appeared to be dose dependent. In former smokers a rebound effect was seen, especially in former heavy smokers, where the risk was sharply increased (relative risk $4 \cdot 4$ ). No sex difference was recorded. Smoking doubled the risk of acquiring Crohn's disease without any dose dependent pattern. In former smokers a non-significantly increased risk was observed. This might be caused by a carry over effect after stopping smoking, however, which possibly is reduced by time. No sex difference was seen.

In 1956 Boller' observed that patients with ulcerative colitis (UC) smoked considerably less than patients with peptic ulcer disease. In 1976 Samuelsson $^{2}$ found that patients with UC significantly more often were non-smokers than matched controls from the general population. Samuelsson considered this to be an effect of the disease, however, and not of aetiologic importance. His observation passed unnoticed until Harries $\mathrm{et}^{\mathrm{al}} \mathrm{l}^{3}$ made the same finding which was confirmed by Jick and Walker ${ }^{4}$ who also found that smoking might reduce the risk of acquiring UC in a dose dependent way. These studies concerned current habits at the time of the investigation and not the smoking pattern at the time of diagnosis or disease onset, which is more important from an aetiologic point of view. This has later been studied by others ${ }^{56}$ and the dominance of non-smokers in patients with UC was evident also as a pre-illness feature. After a discussion in the British Medical Journal, Logan and Langman ${ }^{7}$ recalculated their and others results which fairly strongly indicated that exsmokers suffered an increased risk to develop UC. This finding is possibly supported by a recent study which also showed a reduced risk of acquiring UC in heavy smokers. Only one study ${ }^{5}$ has used fairly

Address for correspondence: Gunnar Järnerot, MD, Division of gastroenterology, Department of Medicine. Örebro Medical Center Hospital, S-701 85 Örebro, Sweden.

Received for publication 4 September 1987 adequate control subjects while the others ${ }^{3+6}$ used other hospital patients as controls which must be considered less appropriate as earlier studies have indicated that hospital controls smoke more than population controls. ${ }^{911}$

The use of inadequate controls might be the reason why the first studies of smoking habits in patients with Crohn's disease (CD) did not show any differences in comparison with the control group. ${ }^{311}$

Later two other studies ${ }^{612}$ showed that patients with $C D$ tended to be smokers to a much higher degree than controls. Only one of them ${ }^{12}$ used an adequate control population. That the smoking habits are very different in UC and CD patients has also been shown by direct comparison between the two groups. ${ }^{1314}$

In a review of epidemiology of inflammatory bowel disease (IBD) Calkins and Mendeloff ${ }^{15}$ commented on the published reports on the influence of smoking: 'It should be noted that several of these reported studies have used prevalent rather than incident cases of UC and CD. Such a practice while advantageous for producing a large enough sample of cases, may introduce biases of unknown direction and magnitude. The studies reported to date have suffered from one or more design problems: low statistical power, inappropriate control groups, lack of adjustment or matching for confounding variables, inadequate smoking history and dose-response information, 
and a dearth of information relating to smoking behaviour and symptoms'.

The aim of the present study was to do a proper controlled study of patients with IBD in order to verify or refute the importance of smoking. The study was approved by the Ethical Committee, Örebro Medical Center Hospital.

\section{Methods}

\section{PATIENTS}

Four hundred and fifty eight patients with IBD attending our colitis clinic were studied. All the patients were living within the immediate catchment area of the hospital where there was no other hospital. These patients represent about $95 \%$ of all diagnosed patients with UC and about $99 \%$ of those with diagnosed $\mathrm{CD}$ living within the area at the time of the study. No attempt was made to collect data about the few patients who had left the area during recent years or the even fewer who had died.

The diagnosis of UC or $\mathrm{CD}$ was based on the clinical history, sigmoidoscopy, radiology of the small and large bowel and/or colonoscopy together with the histology reports and negative faecal culture. When the clinical suspicion of IBD was confirmed by any of these findings the time of diagnosis was considered to be the day of the first clinical examination done at the hospital. As the patients who are referred to us are almost seen immediately, the short time period before the hospital investigation should not be of any major importance. A diagnosis of IBD was made in 38 cases but in these patients we could not definitely differentiate between UC and CD so these were excluded from further analysis.

\section{CONTROLS}

Each patient had two controls from the general population register. These controls were of the same sex and residing within the same postal area as the index patient. They were born on the same day or as closely as possible as the index patient.

\section{QUESTIONNAIRES}

A questionnaire concerning civil status, socioeconomic and educational factors were sent to all patients and control subjects. The smoking questions concerned the life time smoking habits, the type and amount of tobacco consumed and the time for giving up smoking if the patient was an exsmoker. Former smokers were asked about the exact relationship between the time of giving up smoking and the time of diagnosis of IBD. From these questions the smoking pattern at the time of diagnosis could easily be evaluated and also the habits of the controls at the same time. No attempt was done to evaluate the smoking pattern at the time of onset of symptoms as this probably would have given unreliable results. Although we have no hard data on the patient's delay before seeking medical advice, however, we know that in the great majority of patients with IBD in Sweden it is very short at present, and that the doctor's delay until diagnosis of these cases is also very short. Furthermore the questionnaires contained questions about earlier and present gastrointestinal complaints so we believe that no control subject had overt IBD.

\section{ANALYSIS}

The patients and controls were divided into moderate smokers, if they regularly consumed up to 10 cigarettes per day and heavy smokers if they smoked 11 or more cigarettes per day. As few people in Sweden smoke more than 20 cigarettes per day it was not considered meaningful to divide the smokers into further subgroups. Pipe smokers and cigar smokers were excluded from subgrouping as their way of smoking is different from cigarette smokers. As they definitely are or have been exposed to tobacco smoke, however, they were included in the smoking or exsmoking groups when calculating the relative risks.

All subjects who had answered the questionnaire were included in the unmatched analysis while the matched analysis only concerned patients where both or one of their controls had replied. The statistical analyses were performed using multiple logistic regression techniques while controlling for potential confounding variables (sex, age and residence), as described by Breslow and Day. ${ }^{16}$ The relative risks for both matched and unmatched designs were calculated. Although similar risk estimates were obtained independently of which design was used the results regarding both matched and unmatched materials are presented.

Table 1 Response rates to the questionnaire in the ulcerative colitis ( $U C$ ) and Crohn's disease (CD) groups and in their respective control groups

\begin{tabular}{lcc}
\hline & $U C$ & $C D$ \\
\hline Patients approached & 271 & 149 \\
Patients with two controls & 183 & 109 \\
Patients with one control & 69 & 32 \\
Patients without control & 8 & 3 \\
Controls without patients & $20(11)^{*}$ & $9(5)^{*}$ \\
Sets available for matched analysis & 252 & 141 \\
Subjects available for unmatched analysis & 715 & 403 \\
\hline
\end{tabular}

${ }^{*}$ Figures in parentheses refer to patients who did not reply to the questionnaire. 


\section{Results}

QUESTIONNAIRES

Of the 458 patients 277 were residing within the city of Örebro and 181 within other parts of the catchment area. After up to two reminder letters 438 $(95 \%)$ answered the questionnaire. Of the 916 questionnaires sent to the control subjects 778 $(84.9 \%)$ were answered. Of the 38 later excluded patients with IBD 34 had answered the questionnaire. These 38 patients and their control subjects were excluded from further analysis. Table 1 shows the response rates to the questionnaire in patients and control subjects.

\section{PATIENTS}

The mean age at the time of diagnosis of the 260 patients with UC who replied to the questionnaire was 31.6 (median 30.0 ) years and for the 144 patients with CD 29.0 (median 26.0) years. The details regarding age distribution is shown in Table 2 and Table 3 shows the years of diagnosis.

Table 2 Age distribution at the time of diagnosis in patients with ulcerative colitis (UC) or Crohn's disease (CD)

\begin{tabular}{lllllll}
\hline & $n$ & $<20$ & $20-29$ & $30-39$ & $40-49$ & $50+$ \\
\hline UC & 260 & 38 & 89 & 70 & 40 & 23 \\
CD & 144 & 37 & 53 & 27 & 13 & 14 \\
\hline
\end{tabular}

Table 3 Year of diagnosis of ulcerative colitis (UC) or Crohn's disease (CD)

\begin{tabular}{llllll}
\hline & -1964 & $1965-1969$ & $1970-1974$ & $1975-1979$ & $1980-1984$ \\
\hline UC & 33 & 22 & 50 & 84 & 71 \\
CD & 21 & 22 & 28 & 39 & 34 \\
\hline
\end{tabular}

SOCIOECONOMIC, EDUCATIONAL FACTORS AND CIVIL STATUS

No differences were found between the patients with UC or $\mathrm{CD}$ and their controls regarding socioeconomic or educational factors. The civil status was similar in the UC group as in the control group. Of the 86 women with $\mathrm{CD}$, however, 22 had always been single. In their 158 controls this occurred in 19 cases $\left(\chi^{2}=6 \cdot 4, p<0 \cdot 05\right)$. The same but far from significant trend was seen in the 58 men with $C D$ in comparison with their 101 control subjects. Apart from these differences the patients and controls were comparable.

\section{SMOKING}

The type of tobacco consumed and the daily amount as well as the time for giving up smoking was given in detail in all UC patients except two and in all of their controls except 10. This was also the case in six of the control subjects in the $\mathrm{CD}$ group but in none of the $\mathrm{CD}$ patients. These subjects were excluded when analysing the effect of smoking. We have not found, however, that the lack of knowledge in this respect influenced the results in any major way.

\section{ULCERATIVE COLITIS}

Table 4 shows the results in the UC group. The percentage of never smokers was similar in patients $(49 \cdot 2 \%)$ and control subjects $(47 \cdot 6 \%)$. Non-smokers (never smokers + exsmokers) at the time of diagnosis of UC were $72.5 \%$ in the patient group and $58.2 \%$ in the control group $\left(\chi^{2}=13 \cdot 7, p<0 \cdot 001\right)$. Thus the excess of non-smokers at the time of diagnosis in the UC group was the result of a larger number of former smokers $(23 \cdot 2 \%)$ in the patient group than in the control group $(10.6 \%)$ and especially a larger number of heavy exsmokers in the UC group. During

Table 4 Distribution of ulcerative colitis (UC) and controls at the time of diagnosis into never smokers, former smokers and smokers; never smokers being the reference when calculating the relative risks. Results for both unmatched and matched designs are given

\begin{tabular}{|c|c|c|c|c|c|c|c|c|}
\hline & \multirow{2}{*}{$\begin{array}{l}\text { Never } \\
\text { smokers }\end{array}$} & \multicolumn{3}{|c|}{ Formersmokers } & \multicolumn{3}{|l|}{ Sinokers } & \multirow[b]{2}{*}{ Others $\$$} \\
\hline & & $1-10^{*}$ & $11+*$ & All $^{+}$ & $1-10^{*}$ & $11+*$ & All & \\
\hline UC & 127 & 24 & 24 & 60 & 33 & 31 & 71 & 2 \\
\hline Controls & 212 & 25 & 9 & 47 & 69 & 99 & 186 & 10 \\
\hline $\begin{array}{l}\text { Unmatched analysis } \\
\text { Relative risk } \\
\text { p } \\
95 \% \text { confidence interval }\end{array}$ & $1 \cdot 0$ & $\begin{array}{l}1 \cdot 6 \\
0 \cdot 11 \\
0 \cdot 9-3 \cdot 0\end{array}$ & $\begin{array}{l}4 \cdot 5 \\
<0 \cdot 001 \\
2 \cdot 0-10 \cdot 0\end{array}$ & $\begin{array}{l}2 \cdot 2 \\
<0 \cdot 001 \\
1 \cdot 4-3 \cdot 5\end{array}$ & $\begin{array}{l}0.8 \\
0.33 \\
0.5-1 \cdot 3\end{array}$ & $\begin{array}{l}0 \cdot 5 \\
<0 \cdot 01 \\
0 \cdot 3-0 \cdot 8\end{array}$ & $\begin{array}{l}0 \cdot 6 \\
<0 \cdot 05 \\
0 \cdot 4-0 \cdot 9\end{array}$ & \\
\hline $\begin{array}{l}\text { Matched analysis } \\
\text { Relative risk } \\
\text { p } \\
95 \% \text { confidence interval }\end{array}$ & $1 \cdot 0$ & $\begin{array}{l}1 \cdot 7 \\
0 \cdot 13 \\
0 \cdot 9-3 \cdot 2\end{array}$ & $\begin{array}{c}4 \cdot 4 \\
<0 \cdot 001 \\
1.9-10 \cdot 2\end{array}$ & $\begin{array}{c}2 \cdot 3 \\
<0 \cdot 005 \\
1 \cdot 4-3 \cdot 9\end{array}$ & $\begin{array}{l}0 \cdot 8 \\
0 \cdot 31 \\
0 \cdot 5-1 \cdot 3\end{array}$ & $\begin{array}{l}0.5 \\
<0 \cdot 01 \\
0 \cdot 3-0 \cdot 8\end{array}$ & $\begin{array}{l}0 \cdot 7 \\
<0 \cdot 05 \\
0 \cdot 4-0.97\end{array}$ & \\
\hline
\end{tabular}

${ }^{*}$ Number of cigarettes/day; †all former smokers including pipe and cigar smokers and those with unknown daily cigarette consumption; łall smokers including pipe and cigar smokers and those with unknown daily cigarette consumption; §all smoking details unknown. 
the time from diagnosis to the survey, however, a considerable number of patients and controls had given up their habit so that the percentages of smokers then were 17.0 and 33.4 in the two groups respectively - that is, the proportion of new exsmokers was similar in both groups (UC $10.5 \%$, controls $8.4 \%$ ).

Smoking reduced the risk of acquiring UC. The risk reduction was significant only in heavy smokers. No sex differences were found.

Former smoking doubled the risk of contracting $\mathrm{UC}$ and this risk was especially evident in earlier heavy smokers who had a more than four-fold increased risk of acquiring UC. One third of the former smokers who contracted UC did so within two years after stopping smoking, but in many cases the disease developed several years later (range 0-19, mean $6 \cdot 4$, median $5 \cdot 0$ years). Details are shown in Table 5 .

CROHN'S DISEASE

In the CD group, Table 6 , the number of smokers at the time of diagnosis was significantly higher $(56 \cdot 3 \%)$

Table 5 Time relation between the time of diagnosis of ulcerative colitis $(U C)$ or Crohn's disease $(C D)$ and the time for stopping smoking in former smokers

\begin{tabular}{lrc}
\hline Years & $U C$ & $C D$ \\
\hline $0-2$ & 20 & 5 \\
$3-4$ & 8 & 3 \\
$5-6$ & 5 & 3 \\
$7-8$ & 6 & 1 \\
$9-10$ & 7 & 0 \\
$10+$ & 13 & 1 \\
Unknown & 1 & - \\
\hline
\end{tabular}

than in the control group $(41 \cdot 9 \%)\left(\chi^{2}=7 \cdot 0, p<0 \cdot 05\right)$. This was mainly caused by the low proportion of never smokers in the patient group $(34.7 \%)$ in comparison with $50.6 \%$ in the control group. The percentage of exsmokers was very similar in both groups. Smoking doubled the risk of acquiring CD and this risk appeared to be the same in heavy and moderate smokers without any sex differences.

In former smokers the risk of contracting $\mathrm{CD}$ was not significantly increased. The time period between giving up smoking and the diagnosis of $\mathrm{CD}$ varied between $0-11$ (mean $3 \cdot 8$, median 4 ) years. Details are shown in Table 5. Between the time of diagnosis and the survey some of the patients and the controls had given up smoking, so that at the survey the percentages of smokers were 53.5 and 34.7 respectively. Thus in the two control groups the proportion of non-smoking subjects was very similar at the time of the survey.

\section{Discussion}

When doing a case control study the choice of controls is essential. Patients with other diseases are less appropriate as control subjects in a study concerning smoking. ${ }^{911}$ Only three other studies regarding IBD and smoking have used controls from the general population. ${ }^{2512}$ One of these concerned the habits at the time of survey, however, and not the time of diagnosis or onset of symptoms. ${ }^{2}$ Of the two others one has dealt with $U^{\prime s}$ and the other with CD. ${ }^{12}$ Ideally the habit at the onset of symptoms should be analysed in order to get adequate information for aetiologic considerations. This is difficult to define in all patients with IBD, however, while the time of diagnosis is certain. As mentioned earlier

Table 6 Distribution of Crohn's disease (CD) and controls at the time of diagnosis into never smokers, former smokers and smokers; never smokers being the reference when calculating the relative risks. Results for both unmatched and matched designs are given

\begin{tabular}{|c|c|c|c|c|c|c|c|c|}
\hline & \multirow{2}{*}{$\begin{array}{l}\text { Never } \\
\text { smokers }\end{array}$} & \multicolumn{3}{|c|}{ Former smokers } & \multicolumn{3}{|l|}{ Smokers } & \multirow[b]{2}{*}{ Others $\$$} \\
\hline & & $1-10^{*}$ & $11+*$ & All $^{\dagger}$ & $1-10^{*}$ & $11+*$ & All $\neq$ & \\
\hline $\mathrm{CD}$ & 50 & 7 & 4 & 13 & 35 & 39 & 81 & - \\
\hline Controls & 128 & 9 & 8 & 19 & 43 & 53 & 106 & 6 \\
\hline $\begin{array}{l}\text { Unmatched analysis } \\
\text { Relative risk } \\
\text { p } \\
95 \% \text { confidence interval }\end{array}$ & $1 \cdot 0$ & $\begin{array}{l}1 \cdot 9 \\
0 \cdot 23 \\
0 \cdot 7-5 \cdot 4\end{array}$ & $\begin{array}{l}1 \cdot 2 \\
0 \cdot 75 \\
0 \cdot 3-4 \cdot 4\end{array}$ & $\begin{array}{l}1 \cdot 9 \\
0 \cdot 13 \\
0 \cdot 8-4 \cdot 3\end{array}$ & $\begin{array}{c}2 \cdot 0 \\
<0 \cdot 05 \\
1 \cdot 1-3 \cdot 4\end{array}$ & $\begin{array}{c}1.7 \\
<0.05 \\
1.0-2.9\end{array}$ & $\begin{array}{l}2 \cdot 0 \\
<0 \cdot 005 \\
1 \cdot 3-3 \cdot 1\end{array}$ & \\
\hline $\begin{array}{l}\text { Matched analysis } \\
\text { Relative risk } \\
\mathrm{p} \\
95 \% \text { confidence interval }\end{array}$ & $1 \cdot 0$ & $\begin{array}{l}1 \cdot 9 \\
0 \cdot 24 \\
0 \cdot 6-5 \cdot 6\end{array}$ & $\begin{array}{l}1 \cdot 2 \\
0 \cdot 79 \\
0 \cdot 3-5 \cdot 1\end{array}$ & $\begin{array}{l}1 \cdot 9 \\
0 \cdot 15 \\
0 \cdot 8-4 \cdot 3\end{array}$ & $\begin{array}{c}2 \cdot 0 \\
<0 \cdot 05 \\
1 \cdot 1-3 \cdot 4\end{array}$ & $\begin{array}{l}2 \cdot 0 \\
<0 \cdot 05 \\
1 \cdot 1-3 \cdot 5\end{array}$ & $\begin{array}{c}2 \cdot 2 \\
<0 \cdot 005 \\
1 \cdot 3-3 \cdot 5\end{array}$ & \\
\hline
\end{tabular}

${ }^{*}$ Number of cigarettes/day; †all former smokers including pipe and cigar smokers and those with unknown daily cigarette consumption; łall smokers including pipe and cigar smokers and those with unknown daily cigarette consumption; §all smoking details unknown. 
under Methods the time period between onset of symptoms and diagnosis is short in the majority of cases.

As almost all patients with IBD residing within the catchment area of our hospital are referred to us a study of incident instead of prevalent cases would have shown similar results if the recall bias regarding smoking habits is minimal. In our experience smokers and exsmokers are well aware of the time when they started smoking and perhaps even better regarding the date they finished if they are exsmokers. They also very well know the amount of daily tobacco consumption. Thus, the risk of recall bias in this respect is small.

When analysing our control material from different aspects two things deviated from the findings in the patient groups. One was the smoking habits and the other the marital status. In contrast with the findings by Keighley et al, ${ }^{17}$ a larger number of women with $\mathrm{CD}$ in our series had always lived alone compared with their controls. This must be subject for further studies.

In the present study we have confirmed the earlier reports that smoking reduces the risk of acquiring UC in a dose dependent way. ${ }^{47}$ The non-smoking characteristics in UC was evident but this was an effect of a larger number of exsmokers in the UC than the control group as the percentage of never-smokers was the same in both groups. The risk reducing effect of smoking is followed by a rebound phenomenon after giving up smoking. This occurs mainly in heavy smokers who have a more than four-fold increased risk to develop UC. No sex difference was found. The finding of an increased risk in former smokers is in accordance with the reevaluated results of Logan $e t a^{57}$ and also the observation by Benoni and Nilsson. ${ }^{13}$ They found a male dominance of such patients, however, which we could not confirm. This is the first study where a significance of earlier daily cigarette consumption has been shown as a risk factor in a dose dependent way. It is further worth noting the long period many patients had been former smokers before developing UC.

The findings in the CD group were contrary to those in UC. Smoking doubled the risk of acquiring $\mathrm{CD}$ and there did not seem to exist a dose dependent effect. There were no sex differences. That smoking is more prevalent in patients with $\mathrm{CD}$ than in controls both at the time of diagnosis and later during the course of the disease is in accordance with earlier results. ${ }^{612}$ This is mainly because of the low proportion of never smokers in patients with $C D$. Giving up smoking did not increase the risk of contracting CD as the not significantly increased risk in former smokers probably is an effect of time. The median time between giving up smoking and diagnosis of $C D$ was four years but five of the 13 exsmokers had given up smoking one year or less before diagnosis. We interpret this as a carry over effect of smoking in exsmokers which is fairly rapidly eliminated in contrast with the rebound phenomenon seen in UC. In their small series Vessey et $\mathrm{l}^{8}$ also found an increased incidence of $\mathrm{CD}$ in smokers but a normal in exsmokers. Ulcerative colitis and $\mathrm{CD}$ are regarded as multifactorial diseases where several factors such as heredity, immunologic factors, infectious agents, prostaglandins and psychological trauma have been discussed. It is well known that smoking exerts effects both on immune defence and prostaglandin metabolism but if such factors are valid in this respect, what is good in UC is bad in CD. It is also difficult to understand that smoking could cause a change of the immune defence or prostaglandin metabolism in a way so that giving up smoking results in a rebound phenomenon often lasting many years regarding the risk of acquiring UC. A recent study of colonic mucus synthesis in UC showed that non-smoking patients had a significantly lower glycoprotein production than control subjects, but in smoking patients with UC no difference was found in comparison with controls. ${ }^{18}$ This finding is very interesting as to the aetiology of UC and deserves further study. Hypothetically, one could speculate that a subject prone to develop UC has a defective mucus production. When exposed to one or more factors promoting UChe develops the disease. By smoking the defective mucus production might be more or less normalised so that the risk decreases. After stopping smoking this protection ceases, the mucus layer becomes defective again and if the patient becomes exposed to factors promoting UC the disease develops.

Sommerville et al $^{12}$ put forward a hypothesis that there might exist a population with a genetic predisposition to IBD with smoking habit determining which of the two diseases that develops. In a recent study of identical twins, however, we have shown that identical heredity and similar smoking habits are not enough to cause either UC or CD (submitted for publication). One or more aetiologic factors are obviously needed to cause disease, although this does not necessarily go against the hypothesis as such. Very little is known about how smoking affects the location and course of IBD. Holdstock et al ${ }^{14}$ found that smokers generally do worse than non-smokers but this needs further study which we are presently doing. It is obvious, however, that the general negative effects of smoking are so overwhelming that no patient should be encouraged to continue or start smoking as a therapy for UC.

Associate Professor Lennart Bodin and research assistant Inger Fagerlund gave invaluable assistance 
in analysing the data. This study was financially supported by the Swedish ILCO and the Örebro County Research committee. EL and CT have been financially supported for IBD studies by Pharmacia AB, Uppsala, Sweden. This is gratefully acknowledged. This study has in part been reported at the XIX Scandinavian Conference on Gastroenterology, 1986, Faroe Islands.

\section{Addendum}

After preparation of the manuscript two further studies on UC have been published. In spite of a low response rate $(85 \%$ in patients and $62 \%$ in control subjects) Boyko et al ${ }^{\text {p9 }}$ found relative risks very similar to those found by us in current or former smokers. Also the median time of six years or slightly more that elapsed before former smokers developed UC was similar to our finding. In another study ${ }^{211}$ the mean time was found to be $5 \cdot 7$ years.

\section{References}

1 Boller R. Erfahrungen an 89 Colitis-ulcerosa-Fällen der Abteilung Boller im Allgemeinen Krankenhaus Wien. Gastroenterologia 1956; 86: 693-6.

2 Samuelsson SM. Ulcerös kolit och proktit. Uppsala: Department of Social Medicine. University of Uppsala: Thesis, 1976: 128.

3 Harries AD, Baird A, Rhodes J. Non-smoking: a feature of ulcerative colitis. Br Med J 1982; 284: 706.

4 Jick H, Walker AM. Cigarette smoking and ulcerative colitis. N Engl J Med 1983; 308: 261-3.

5 Logan RFA, Edmond M, Sommerville KW, Langman MJS. Smoking and ulcerative colitis. Br Med J 1984; 288: 751-3.

6 Thornton JR, Emmett PM, Heaton KW. Smoking, sugar, and inflammatory bowel disease. $\mathrm{Br}$ Med J 1985; 290: $1786-7$.
7 Logan R, Langman MJS. Smoking and ulcerative colitis [Letter]. Br Med J 1984; 288: 1307.

8 Vessey M, Jewell D, Smith A, Yeates D, McPherson K. Chronic inflammatory bowel disease, cigarette smoking and use of oral contraceptives: findings in a large cohort study of women of childbearing age. $\mathrm{Br}$ Med J 1986; 292: 1101-3.

9 Doll R, Hill AB. A study of the etiology of carcinoma of the lung. Br Med J 1952; 13: 1271-86.

10 Collaborative group for the study of stroke in young women. Oral contraception and increased risk of cerebral ischemia or thrombosis. N Engl J Med 1973; 288: $871-8$.

11 Mayberry JF, Rhodes J, Newcombe RG. Breakfast and dietary aspects of Crohn's disease. $B r \operatorname{Med} J$ 1978; ii: 1401.

12 Somerville $\mathrm{KW}$, Logan RFA, Edmond M, Langman MJS. Smoking and Crohn's disease. Br Med J 1984; 289: 954-6.

13 Benoni C, Nilsson $\AA$. Smoking habits in patients with inflammatory bowel disease. Scand J Gastroenterol 1984; 19: 824-30.

14 Holdstock G, Savage D, Harman M, Wright R. Should patients with inflammatory bowel disease smoke? $\mathrm{Br}$ Med J 1984; 288: 362.

15 Calkins BM, Mendeloff AI. Epidemiology of inflammatory bowel disease. Epidemiol Rev 1986; 8: 60-91.

16 Breslow NE, Day NE. Statistical methods in cancer research. Vol 1 - The analysis of case-control studies. Int Agency Res Cancer 1980: 192-279.

17 Keighley A, Miller DS, Hughes AO, Langman MJS. The demographic and social characteristics of patients with Crohn's disease in the Nottingham area. Scand $J$ Gastroenterol 1976; 11: 293-6.

18 Cope GF, Heatley RV, Kelleher J. Smoking and colonic mucus in ulcerative colitis. $\mathrm{Br}$ Med $J$ 1986; 293: 481 .

19 Boyko EJ, Koepsell TD, Perera DR, Inui TS. Risk of ulcerative colitis among former and current cigarette smokers. N Engl J Med 1987; 316: 707-10.

20 Motley RJ, Rhodes J, Ford GA, et al. Time relationships between cessation of smoking and onset of ulcerative colitis. Digestion 1987; 37: 125-7. 